\title{
A REVIEW OF THE UTILITY OF EEG DEPTH OF ANAESTHESIA MONITORS IN THE PAEDIATRIC INTENSIVE CARE ENVIRONMENT
}

\section{Authors}

Stephen McKeever, R.G.N, RN (Child), ENB 415, BSc (Hons) ${ }^{1,2,3}$

Current relevant appointment - PhD candidate

Linda Johnston RN, $\mathrm{PhD}^{2,3,4}$

Current relevant appointment - Professor and Head of School of Nursing \& Midwifery

Andrew Davidson MBBS, FANZCA, GradDipEdBiostat, MD1,2

Current relevant appointment - Group Leader, Anaesthesia Research

1 Department of Anaesthesia and Pain Management, Royal Children's Hospital, Melbourne, Australia

2 Murdoch Childrens Research Institute, Melbourne, Australia

3 Melbourne School of Health Sciences, The University of Melbourne, Australia

4 School of Nursing \& Midwifery, Queen's University Belfast, United Kingdom

Correspondence to:

Stephen McKeever

Address: Department of Anaesthesia \& Pain Management, Royal Children's Hospital, Flemington Road, Parkville 3052, Victoria, Australia

Email: stephen.mckeever@rch.org.au

Telephone: +61 (0) 422526992

Facsimile: $+61(0) 393456003$

Keywords: Electroencephalogram, Paediatric Intensive care, sedation assessment 
Objectives

\section{SUMMARY}

This paper aims to bring together current evidence regarding the use of depth of anaesthesia monitors (DoAM) as objective measures of sedation for paediatric intensive care (PIC) patients.

Background

Delivering appropriate dosages of sedative agents, to individual PIC patients, is important to reduce the many risks of over- or under- sedation. Although based on adult anaesthesia, DoAMs could offer increased objectivity to the titration of sedative agents for children in PIC. This article synthesises the current available evidence from studies investigating DoAM use in the PIC environment

Method

Literature regarding DoAM use in PIC was reviewed, from 1996 and August 2011, after EMBASE, PubMed, CINAHL and ProQuest Dissertation \& Theses Database were searched using key search terms.

Results

Fourteen original research articles addressing sedation assessment using DoAMs in PIC were identified. The main findings were that DoAMs generally have a moderate or poor correlation with sedation scores and their performance varies in varying clinical settings. DoAMs do not make reliable conclusions about depth of sedation of individual PIC children, and can be influenced by children's age.

Conclusion

Evidence to support DoAM's in the PIC setting is currently not sufficient to advocate their routine use in clinical practice. 


\section{INTRODUCTION}

Ensuring children receive appropriate levels of sedation is a daily challenge for paediatric intensive care (PIC) practitioners (Tobias 2000). Somnolent agents are generally commenced according to the child's weight (Zuppa et al. 2005). Evaluating responses to these medications often relies on haemodynamic monitoring and reaction to stimuli (Playfor et al. 2003). Evaluations can also be augmented with sedation scoring systems (Long et al. 2005) such as the Ramsay Sedation Scale (RSS) (Ramsay et al. 1974), the original COMFORT score (Ambuel et al. 1992) or the later COMFORT "behavior" scale (COMFORT B) (Ista et al. 2005). However, elements of these sedation scoring systems are subjective (Sadhasivam et al. 2006). In addition, sedation scales assess patient movement in response to stimuli (Schmidt 2006). Thus have an inherent limitation for patients receiving neuromuscular blockade (NMB) (Tobias 2005). Electroencephalogram (EEG) analysis, using commercially available depth of anaesthesia monitors (DoAM), may provide an objective method to assess children's sedation in PIC (Aneja et al. 2003).

Two such DoAMs are the Bispectral Index monitor ${ }^{\mathrm{TM}}$ (Aspect Medical Systems, Inc. Norwood, USA) and Alaris Auditory Evoked Potentials (AEP) monitor (ALARIS Medical Systems, Danmeter A/S, Odense, Denmark). The Bispectral Index (BIS) algorithm analyses spontaneous EEG information from the, time domain, bispectrum, and frequency domain, to generate a single dimensionless number (Rampil 1998). The AEP Monitor uses active acoustic stimulation, delivered through headphones, to generate middle latency auditory evoked potentials (MLAEP) (Kurita et al. 2001). Anaesthetics or sedation alters EEG latency and amplitude (Drummond 2000; Thornton and Sharpe 1998) and these changes are used to generate the A-line ARX Index ${ }^{\mathrm{TM}}$ (AAI) (Mantzaridis and Kenny 1997). BIS and AAI have a range from zero, where patient's EEG is isoelectric, to 100 , when patients are awake (Nishiyama and Hanaoka 2004; Rampil 1998). To achieve desired levels of anaesthesia or sedation, medications can be titrated according to the displayed index. Both monitors were developed using adult EEG data and calibrated during adult anaesthesia (Drummond 2000; Johansen and Sebel 2000; Tempe 2001) 
Intensive care researchers have investigated DoAMs to assess sedation levels for critically ill adults (De Deyne et al. 1998; Simmons et al. 1999). Using these monitors in adult intensive care however, remains controversial (Alexander and Duane 2005; Rinaldi et al. 2006). Much of this controversy has surrounded evaluating DoAMs without a comparable gold standard of sedation measurement (Alexander and Duane 2005), wide inter-individual DoAM values at the same sedation scores (Frenzel et al. 2002) and electromyographic interference influencing DoAM outputs (Nasraway et al. 2002).

DoAM use in PIC is also an area of active research. To date, the most comprehensive review examining the uses and limitations of BIS, MLAEP, and several clinical sedation scoring systems to evaluate PIC sedation was conducted by Lamas and Lopez-Herce (2010). Whilst only briefly mentioning the methods used in their review, Lamas and LopezHerce (2010) conclude that there is currently no ideal mode to assess sedation for PIC patients. However, BIS may be beneficial for monitoring older children during deep sedation and NMB. A commentary by Playfor (2005) and an editorial by Tobias (2005) advise that more evidence is required before BIS can be supported in PIC. Another non-systematic review, concluded by Dominguez and Helfaer (2006), examined BIS utility in paediatric emergency and intensive care departments. This review reported that due to the range of BIS scores, especially at lighter levels of sedation, BIS utility is limited without further investigation. This current article aims to provide a systemic review, which re-examines and updates available evidence, with a particular focus on the clinical utility of DoAMs to monitor sedation in PIC.

\section{METHODS}

This review was based on the National Health and Medical Research Council (NHMRC) (1999b) guidelines for systematic identification and review of scientific literature. The databases EMBASE, PubMed and CINAHL were searched between the dates January 1996 and August 2011. The starting date was chosen as the Bispectral Index ${ }^{\mathrm{TM}}$ monitor (Aspect Medical Systems Inc., Newton, MA), the first and most studied DoAM, was 
approved by the US Food and Drug Administration for use in 1996 (Rosow and Manberg 2001). The search terms used, both alone and in combination, to identify words in the title, original title, abstract, name of substance, subject heading and unique identifiers of articles were; depth, anesthesia, anaesthesia, monitor, hypnotics, sedative, sedation, electroencephalography, Bispectral index, Narcotrend, Entropy, Ramsey, COMFORT, critical care, intensive care, paediatric, and pediatric. ProQuest Dissertation and Theses Database were also searched for the above words in citations or abstracts. Searches were limited to studies that included children from birth to adolescent. In addition, "snowballing" searches of articles bibliographies identified further relevant studies.

Studies evaluating DoAMs to monitor sedation in the PIC population were selected. Articles not published in English were excluded. Articles were assessed according to the NHMRC (1999a) evidence hierarchy, as detailed in Table 1. Due to limited published material on the subject, study designs with an Evidence Level of IV and above were included. Studies that reported correlations were considered, slight at an $r^{2}=0.04$ to 0.15 , moderate $r^{2}=0.16$ to 0.49 , and strong $r^{2}=0.5$ to 1.0 .

Table 1 Evidence Hierarchy (National Health and Medical Research Council 1999a, p. 56)

\begin{tabular}{cl}
\hline $\begin{array}{c}\text { Evidence } \\
\text { Level }\end{array}$ & \multicolumn{1}{c}{ Study design } \\
\hline I & $\begin{array}{l}\text { Evidence obtained from a systematic review of all relevant } \\
\text { randomised controlled trials } \\
\text { Evidence obtained from at least one properly designed randomised } \\
\text { controlled trial }\end{array}$ \\
II & $\begin{array}{l}\text { Evidence obtained from well-designed pseudo-randomised } \\
\text { controlled trials (alternate allocation or some other method) } \\
\text { III-1 }\end{array}$ \\
III-2 & $\begin{array}{l}\text { Evidence obtained from comparative studies with concurrent } \\
\text { controls and allocation not randomised (cohort studies), case }\end{array}$ \\
control studies, or interrupted time series with a control group \\
III-3 & $\begin{array}{l}\text { Evidence obtained from comparative studies with historical control, } \\
\text { two or more single-arm studies, or interrupted time series without a } \\
\text { parallel control group. } \\
\text { Evidence obtained from case series, either post-test or pre-test and } \\
\text { post-test }\end{array}$ \\
\hline
\end{tabular}




\section{RESULTS}

\section{Study descriptions}

Fourteen articles evaluating DoAM in the PIC population were identified and included for review (Aneja et al. 2003; Berkenbosch et al. 2002; Courtman et al. 2003; Crain et al. 2002; Froom et al. 2008; Lamas et al. 2008a; Lamas et al. 2008b; Lamas et al. 2009a; Lamas et al. 2009b; Prins et al. 2007; Tobias and Grindstaff 2005; Triltsch et al. 2005; Trope et al. 2005; Twite et al. 2005). Most studies were prospective, and observational studies, apart from Trope and collegues (2005), who undertook a retrospective chart review. Review using the evidence hierarchy identified that a majority of studies had low level evidence, shown in Table 2. A notable exception was Lamas and colleague's (2009b) study with an evidence level III-2, which compared postoperative cardiac children to a control group of postoperative non-cardiac children.

The number of patients included in the reviewed studies was 552 (sample size range 8 to 81) and participants ranged in age from 10 days to 20 years. Many patients had repeated observations giving a total of 167906 observations. Data from two studies were excluded from these calculations; Prins et al (2007) did not report the number of observations used; and Lamas et al. (2009a) conducted a re-examination of data collected by Lamas et al.(2008b) and therefore was not included in the overall numbers of patients or total observations. Triltsch et al. (2005) was the only study to include only one observation from each patient. All patients studied were ventilated with a tracheal tube and required sedation. Key features of the reviewed studies are summarised in Table 2. 
Table 2 Summary of studies included in the review

\begin{tabular}{|c|c|c|c|c|c|}
\hline Study summary & $\begin{array}{l}\text { Depth of } \\
\text { anaesthesia } \\
\text { monitor } \\
\text { (software version) }\end{array}$ & $\begin{array}{l}\text { Comparative } \\
\text { parameter/s }\end{array}$ & $\begin{array}{c}\text { Population } \\
(\mathrm{N}) \\
\text { Age } \\
\text { Number of observations }\end{array}$ & Main findings & $\begin{array}{l}\text { Evidence } \\
\text { level }\end{array}$ \\
\hline $\begin{array}{l}\text { Aneja et al. (2003) compared the BIS } \\
\text { to RSS in sedated children } \pm \text { NMB }\end{array}$ & BIS (not stated) & RSS & $\begin{array}{c}48 \\
\text { Range } 0.5 \text { to } 19 y r s \\
933\end{array}$ & $\begin{array}{l}\text { RSS and BIS demonstrated a strong } \\
\text { correlation in children not receiving NMB } \\
\left(r^{2}=0.59\right) .\end{array}$ & III-3 \\
\hline $\begin{array}{l}\text { Berkenbosch et al. (2002) } \\
\text { examined the correlation of BIS with } \\
\text { three sedation scores in PIC } \\
\text { patients. }\end{array}$ & BIS (not stated) & $\begin{array}{l}\text { PICUSS mRSS } \\
\text { TSS }\end{array}$ & $\begin{array}{c}24 \\
\text { Range } 1 \text { mo to } 20 \text { yrs } \\
428\end{array}$ & $\begin{array}{l}\text { Slight to moderate correlation between the } \\
\text { sedation scores and BIS (PICUSS } r^{2}=0.21 \text {, } \\
\left.\text { mRSS } r^{2}=0.59, \text { TSS } r^{2}=0.09\right) \text {. }\end{array}$ & IV \\
\hline $\begin{array}{l}\text { Courtman et al. (2003) investigated } \\
\text { the correlation of BIS with } \\
\text { COMFORT in sedated children, } \pm \\
\text { neurological compromise, at times of } \\
\text { endotracheal tube suction. }\end{array}$ & BIS (3.1) & COMFORT & $\begin{array}{c}40 \\
\text { Range } 1 \text { mo to } 16 \text { years } \\
373\end{array}$ & $\begin{array}{l}\text { Overall, BIS and COMFORT demonstrated a } \\
\text { moderate correlation }\left(r^{2}=0.25\right) \text {. The correlation } \\
\text { was weaker in the neurological compromised } \\
\text { patient }\left(r^{2}=0.06\right) \text {. }\end{array}$ & IV \\
\hline $\begin{array}{l}\text { Crain et al.(2002) examined the } \\
\text { correlation of BIS with COMFORT } \\
\text { scores in patients without NMB }\end{array}$ & BIS (not stated) & COMFORT & $\begin{array}{l}31 \\
\text { Mean } 53 \text { months } \\
\text { Median } 25 \text { months } \\
140\end{array}$ & $\begin{array}{l}\text { BIS and COMFORT demonstrated a moderate } \\
\text { correlation }\left(r^{2}=0.26\right) \text {. }\end{array}$ & IV \\
\hline $\begin{array}{l}\text { Froom et al. (2008) investigated BIS } \\
\text { from right and left hemispheres, peri- } \\
\text { physiotherapy, for asymmetry. They } \\
\text { also assessed BIS changes with } \\
\text { stimulation. }\end{array}$ & BIS XP (3.12) & COMFORT & $\begin{array}{c}19 \\
\text { Range } 0.55 \text { to } 9.7 \text { yrs } \\
84\end{array}$ & $\begin{array}{l}\text { BIS values were different depending on the } \\
\text { hemisphere monitored. Correlations of BIS } \\
\text { (mean) with COMFORT reduced with } \\
\text { stimulation from } r^{2}=0.36 \text { to } r^{2}=0.15 \text {. }\end{array}$ & IV \\
\hline $\begin{array}{l}\text { Lamas et al. (2008a) examined the } \\
\text { correlation of sedation scoring } \\
\text { systems to DoAMs in patient's } \pm \\
\text { NMB }\end{array}$ & $\begin{array}{l}\operatorname{BIS~XP~(3.4)~} \\
\operatorname{AEP}(1.5)\end{array}$ & $\begin{array}{l}\text { COMFORT, } \\
\text { mRSS, } \\
\text { HR, BP }\end{array}$ & $\begin{array}{c}77 \\
\text { Range } 15 \text { days to } 19 \text { yrs } \\
234\end{array}$ & $\begin{array}{l}\text { Children without muscle relaxants showed } \\
\text { moderate to good correlation between DoAM's } \\
\text { clinical sedation scores (highest correlation } \\
\text { BIS with mRSS } r^{2}=0.49 \text { and lowest correlation } \\
\text { BIS with COMFORT } r^{2}=0.23 \text { ). }\end{array}$ & IV \\
\hline $\begin{array}{l}\text { Lamas et al. (2008b) compared the } \\
\text { DoAMs and sedation scores after } \\
\text { children received three types of }\end{array}$ & $\begin{array}{l}\operatorname{BIS~XP}(3.4) \\
\operatorname{AEP}(1.5)\end{array}$ & $\begin{array}{l}\text { COMFORT, } \\
\text { mRSS, } \\
\text { HR, BP }\end{array}$ & $\begin{array}{c}81 \\
\text { Range } 15 \text { days to } 19 \text { yrs } \\
240\end{array}$ & $\begin{array}{l}\text { All stimuli increased BIS values. AAI increased } \\
\text { only with painful stimuli but not those receiving } \\
\text { NMB. }\end{array}$ & IV \\
\hline
\end{tabular}


stimuli: auditory, tactile and painful. Lamas et al.(2009a), re-examined data from Lamas et al.(2008b) and, investigated other EEG parameters for variations according to age and sedation level

Lamas et al. (2009b) investigated the utility of DoAMs to assess sedation in children post cardiac surgery. The study used post non-cardiac surgery controls from Lamas et al. (2008a).

Prins et al.(2007) examined BIS to monitor burst suppression during

barbituate coma

Tobias and Grindstaff (2005)

compared BIS values to nursing staf assessment of sedative agent requirement during $\mathrm{NMB}$.

Triltsch et al. (2005) examined the correlation of BIS to COMFORT scores in patients without NBM.

Trope et al. (2005) assessed

$$
\begin{array}{cc}
\text { BIS XP (3.4) } & \text { SEF, SR, EMG, } \\
\text { AEP (1.5) } & \text { MLAEP }
\end{array}
$$

\section{BIS XP (3.4)}

AEP (1.5)

COMFORT, mRSS, HR, BP

50

Less than 6 months, $\mathrm{n}=17$

6 months to 2 years, $n=23$

2 to 14 years, $n=10$

98

BIS (3.12)

cEEG , Barbiturate plasma levels

BIS (not stated) Clinical nurse

assessment

BIS (3.12)

COMFORT

BIS (not stated)

HR/MAP
98
8

Range 4 months to $15 \mathrm{yrs}$ Not reported

$$
12
$$

Range 1 to 12 year/s 161893

40

Range 21 days to 16 years 40

47

Range 10 days to 18 years 2574

changes in HR/MAP values in NMB \pm

vasoactive medications.

Twite et al. (2005) investigated the

BIS (3.21)

75

COMFORT

75

Range 1 month to 12 years 869

BIS: Bispectral Index ${ }^{\mathrm{TM}}$ (Aspect Medical Systems Inc., Newton, MA)

AEP: Auditory Evoked Potential monitor TM (Alaris Medical Systems, Danmeter A/S, Odense, Denmark)

AAl: A-line ${ }^{\mathrm{TM}}$ ARX-Index (Alaris Medical Systems, Danmeter A/S, Odense, Denmark)

COMFORT: COMFORT sedation score (Ambuel et al. 1992)

[m]RSS: [modified] Ramsey Sedation Scale (Ramsay et al. 1974)

SR: Suppression Ratio

MLAEP: Middle latency auditory evoked potentials

Cardiac and non cardiac groups demonstrated

no significant differences in mean values of $\mathrm{AAI}$ and COMFORT. BIS and mRSS were lower in the cardiac group compared to control group.

Average correlation been cEEG SR and BIS

SR was moderate $\left(n=4, r^{2}=0.46\right)$.

Barbiturate levels related poorly to the SR.

Excessive sedatives are often administered

during NMB when sedation assessed by hemodynamic variables.

Overall there was moderate correlation of BIS to COMFORT scores $\left(r^{2}=0.42\right)$

Poor association with changes in BIS and physiological variables.

Overall there was moderate correlation of BIS

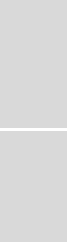


SEF: Spectral Edge Frequency 95\%

EMG: Electromyogram

cEEG: Conventional EEG

TSS: Tracheal Suctioning Score (Parkinson et al. 1997)

PICUSS: Paediatric Intensive Care Sedation Score (Berkenbosch et al. 2002)

HR: Heart Rate, BP: Blood Pressure, MAP: Mean Arterial Blood Pressure, NMB: Neuromuscular Blockade 


\section{$\underline{\text { Heterogeneity of measures }}$}

All 14 studies included in this review investigated the BIS ${ }^{\mathrm{TM}}$ monitor and four studies also included the AEP monitor (Lamas et al. 2008a; Lamas et al. 2008b; Lamas et al. 2009a; Lamas et al. 2009b). Four different sedation scoring systems were used. Eight studies investigated COMFORT (Courtman et al. 2003; Crain et al. 2002; Froom et al. 2008; Lamas et al. 2008a; Lamas et al. 2009b; Triltsch et al. 2005; Twite et al. 2005). Five studies investigated RSS (Aneja et al. 2003; Berkenbosch et al. 2002; Lamas et al. 2008a; Lamas et al. 2008b; Lamas et al. 2009b). One study investigated the Tracheal Suctioning Score together with the Paediatric Intensive Care Sedation Score (Berkenbosch et al. 2002). Physiological parameters of heart rate and blood pressure were also included in four studies (Lamas et al. 2008a; Lamas et al. 2008b; Lamas et al. 2009b; Trope et al. 2005). In addition, DoAMs were assessed in a variety of clinical situations. Studies examined the applicability of DoAMs during the care of sedated PIC patients without NMB (Berkenbosch et al. 2002; Crain et al. 2002; Triltsch et al. 2005; Twite et al. 2005) and with NMB (Aneja et al. 2003; Lamas et al. 2008a; Tobias and Grindstaff 2005; Trope et al. 2005). Other studies compared postoperative cardiac and non cardiac patients (Lamas et al. 2009b), patients receiving a variety of stimuli (Lamas et al. 2008b), peri-physiotherapy (Froom et al. 2008), peri-endotracheal suction (Courtman et al. 2003) and children during barbiturate coma (Prins et al. 2007).

\section{Electroencephalogram monitors studied}

A variety of BIS algorithm versions were investigated and ranged from BIS V3.1 to BIS XP V3.4. Five studies did not report the BIS software version used (Aneja et al. 2003; Berkenbosch et al. 2002; Crain et al. 2002; Tobias and Grindstaff 2005; Trope et al. 2005). In four studies investigating the AEP monitor version 1.5 was used (Lamas et al. 2008a; Lamas et al. 2008b; Lamas et al. 2009a; Lamas et al. 2009b).

\section{Excluded participants}

Most of the studies excluded patients with underlying neurological involvement as these conditions could alter children's EEG and potentially influence the DoAM indices (Crain et al. 2002; Froom et al. 2008; Tobias and Grindstaff 2005; Twite et al. 2005). Exceptions to 
this were; Courtman et al.(2003) who included 15 patients with a head injury or an encephalopathy, Berkenbosch et al. (2002) who included one patient with a closed head injury and another with hypertensive encephalopathy, and Prins et al. (2007) who investigated children with traumatic brain injuries or seizure disorders receiving a barbiturate induced coma.

Ketamine at sedative doses has been shown to increase EEG theta power and reduce delta power (Suzuki et al. 1998) and may lead to paradoxically higher BIS values, especially when given in conjunction with propofol (Sakai et al. 1999). The use of ketamine is therefore an important consideration in studies examining BIS. Apart from two children in the Triltsch et al.(2005) study, no other children were reported to have received ketamine.

\section{Examinations of DoAMs and sedation scoring systems}

A majority of the reviewed studies utilised PIC nurses to conduct sedation score assessments. Apart from two studies, Berkenbosch et al. (2002) and Courtman et al.(2003), nurses were blinded to DoAM information. Three studies used independent observers (Crain et al. 2002; Triltsch et al. 2005; Twite et al. 2005). Crain et al. (2002) used two independent observers with a pre-study assessment of interrater reliability (Cronbach's alpha $>0.9$ ) but did not report any blinding to the BIS during the study. Trope et al.(2005) did not include DoAM blinding as it was a retrospective chart review.

Most studies correlated BIS with the COMFORT sedation scoring system; which was developed and validated by Ambuel and collegues (1992) to quantify children's distress during PIC. Several studies reported an overall moderate degree of correlation between BIS and COMFORT score ranging from $r^{2}=0.23$ (Lamas et al. 2008a) to $r^{2}=0.42$ (Triltsch et al. 2005). However, during certain clinical situations this correlation was shown to be lower. Lamas and collegues (2009b) found lower BIS and COMFORT correlations in postoperative cardiac $\left(r^{2}=0.12\right)$, and non-cardiac patients $\left(r^{2}=0.16\right)$. Indicating that neurological abnormalities do influence the BIS values, Courtman et al. (2003), found that when patients with head injuries or encephalopathy's were included in the analysis, there was a reduction in the BIS and COMFORT correlation from $\mathrm{r}^{2}=0.25$ to $\mathrm{r}^{2}=0.06$. Froom et al. 
(2008) examined BIS and COMFORT values, obtained peri-physiotherapy. This physiotherapy included endotracheal suction and sometimes physiotherapy fibrillation, percussion, and patient turning. The results demonstrated BIS and COMFORT correlations were lower during physiotherapy $\left(r^{2}=0.15\right)$ compared to pre- and post- physiotherapy $\left(r^{2}=0.36\right)$.

In Triltsch and collegues (2005) study, a post hoc analysis that excluded two children that received ketamine, showed that BIS to COMFORT correlation improved slightly from $r^{2}=0.42$ to $r^{2}=0.45$. Triltsch and collegues (2005) also found BIS and COMFORT scores had high correlations when obtained in children aged less than six months $\left(r^{2}=0.61\right)$ but lower in children older than six months $\left(r^{2}=0.22\right)$.

Another sedation scoring system investigated was a modified version of the Ramsay Sedation Scale (mRSS). Originally the Ramsay scale was developed to assess sedation in the adult intensive care environment (Ramsay et al. 1974). Despite not having had initial validity and reliability testing, when applied to adult patients, the Ramsay Scale has shown good correlation with the Sedation-Agitation Scale (Riker et al. 1999) and Observer's Assessment of Alertness and Sedation (Hernández-Gancedo et al. 2006). From the reviewed studies there was a larger range in correlations of BIS with mRSS than was found when BIS was compared with COMFORT. At the lower end, Berkenbosch and colleagues (2002) reported a slight correlation of BIS with mRSS $\left(r^{2}=0.12\right)$ whilst Aneja et al. (2003) found a strong correlation of $r^{2}=0.59$. In the study by Lamas et al. (2009b), the BIS to mRSS correlation in postoperative cardiac children was $r^{2}=0.45$, and in the postoperative non-cardiac patients it was $r^{2}=0.39$. Berkenbosch et al. (2002) presented BIS values obtained at each mRSS level. This provides an insight into the range of values that BIS can provide in various clinical states. In the group of children who were evaluated as mRSS 1 (patient is under-sedated and is anxious, agitated and restless) the mean BIS value was 54 with an interquartile BIS range of 44 to 76 and a range of 18 to 98 . When patients were evaluated as mRSS 6 (patient is over-sedated and has no response to a light glabellar tap, loud noise or voice) the mean BIS was 36 with an interquartile BIS range of 24 to 54 and a 
range of 8 to 91 . This indicates that to differentiate between these quite different clinical states, BIS monitoring may be of little clinical utility.

Assessing another element of the BIS monitor, Froom and colleagues (2008) compared the COMFORT sedation scoring system and BIS during tracheal suctioning. The authors investigated potential asymmetry of BIS readings taken from different sides of the forehead region. They found a discrepancy between the mean left and right BIS readings prephysiotherapy; $9.2,95 \% \mathrm{Cl}[5.9,12.5]$, during physiotherapy; $15.8,95 \% \mathrm{Cl}[11.9,19.7]$ and post-physiotherapy; 7.5, 95\% Cl [5.2, 9.7]. Froom and colleagues (2008) finding, not only emphasises that choice of BIS position during clinical use is important, it also identifies sensor position as a possible confounding factor that is not reported to have been accounted for in other studies.

Fewer studies examined the correlation of AAI or MLAEP with both COMFORT and mRSS sedation scoring systems. Lamas et al. (2008a), found there was an overall moderate correlation between $\mathrm{AAI}$ and COMFORT $\left(\mathrm{r}^{2}=0.28\right)$ and AAI and mRSS $\left(\mathrm{r}^{2}=0.35\right)$. Correlations remained moderate during a sub analysis of children aged less than 6 months, 6 months to 2 years and more than 2 years of age. A later study by Lamas and collegues (2009b), found a moderate degree of correlation between MLAEP and both the COMFORT and mRSS in both postoperative cardiac, and non-cardiac, patients. As Lamas et al. (2008a) and Lamas et al. (2009a) were not able to demonstrate strong correlations between the EEG-derived indices and the clinical sedation scoring systems, it indicates that like BIS, the AEP monitor may not be suitable for PIC patients.

BIS was also found to have slight or moderate correlation with two other sedation scoring systems. Berkenbosch colleagues (2002) included the Paediatric Intensive Care Sedation Score (Berkenbosch et al. 2002) and the Tracheal Suctioning Score, which is a sedation scale that assesses a child's response post- tracheal suctioning (Parkinson et al. 1997). The Paediatric Intensive Care Sedation Score overall correlation with BIS was moderate $\left(r^{2}=0.21\right)$ and BIS correlation with the Tracheal Suctioning Score was slight $\left(r^{2}=0.08\right)$. 
Two other interesting observations, which might have clinical relevance, were reported by Lamas and collegues (2009b). In post-cardiac surgery children receiving active heart pacing, the AEP monitor was unable to provide the MLAEP due to excessive artefact and, in patients able to have their cardiac pacemakers suspended, the BIS value rose by 10 to 15 points. Within the PIC environment a cardiac pacemaker is a common mode of therapy (Valsangiacomo et al. 2002). During pacing, artefact contamination, of either the AEP or BIS monitor outputs, may provide spurious values to the unwitting user.

Lamas and colleagues (2008a) utilised an approach that compared baseline recordings of COMFORT, mRSS, BIS, and AAI, to values obtained during auditory, tactile and painful stimuli. In response to all three stimuli there was a statistically significant increase in BIS and COMFORT values. The only statistically significant increase in AAI was in response to painful stimuli, and the mRSS in response to tactile stimuli. It is reported that although the differences were statistically significant the changes were of small magnitude and therefore not clinically significant.

\section{DoAMs and physiological parameters}

In the PIC setting, decisions regarding a child's appropriate level of sedation are traditionally made by assessing clinical signs. The utility of physiological parameters as appropriate measures of sedation has been questioned (Ista et al. 2005). Three reviewed studies investigated the correlation of DoAMs with physiological parameters (Lamas et al. 2008a; Lamas et al. 2008b; Lamas et al. 2009b). Lamas and colleagues (2008a) found no correlation of BIS with heart rate $(\mathrm{HR})\left(\mathrm{r}^{2}=0.008\right)$, and slight correlation between BIS and systolic BP (SBP) $\left(r^{2}=0.08\right)$, and diastolic BP (DBP) $\left(r^{2}=0.06\right)$. Similar low correlations were reported between AAI and the autonomic variables for patients with and without NMB. In response to three stimuli, the autonomic variables of $\mathrm{HR}$, SBP and DBP did not change significantly from baseline values (Lamas et al. 2008b). In addition, Lamas and colleagues' later study (2009b) found no correlation between the same autonomic variables and BIS or MLAEP. Patients in PIC receive many interventions and medications that, independent of the patient's level of consciousness, can alter HR or blood pressure (Ista et al. 2005). 
These studies highlight that using physiological parameters to monitor sedation, in PIC patients, may have little relationship to a child's underlying depth of sedation.

\section{Assessing children during NMB}

When NMB is used, evaluation of the patient's underlying sedation level using sedation scoring systems which require an assessment of movement in response to stimuli, are of little value (Tobias 2005). Not surprisingly, studies reported lower correlations of DoAM to sedation scoring systems when children were receiving NMB compared to those who were not (Lamas et al. 2008a; Lamas et al. 2009b).

Other approaches to examine the complex issue of evaluating sedation of children during NMB were made by Trope et al. (2005), Tobias and Grindstaff (2005), and Lamas et al. (2008b). Trope et al. (2005) retrospectively reviewed the charts of children receiving NMB and continuous BIS monitoring. Periods where BIS readings were $\geq 30 \%$ different from baseline were assessed for an associated $\geq 10 \%$ change from baseline in HR and mean arterial pressure (MAP) recordings. Overall, MAP changes were concomitant with BIS changes from $23.8 \%$ of the readings, whilst HR only $10.6 \%$ and the combined HR + MAP only showed agreement with $5.7 \%$ of the recordings. A sub analysis was performed with patients receiving vasoactive medications, such as $\alpha$ - and/or $\beta$ - adrenergic medications, and those who did not. From patients who received vasoactive medications $28.3 \%$ had BIS values that corresponded with MAP changes, this was significantly better than the $17.2 \%$ without vasoactive medications $(p<0.05)$. HR and HR + MAP recordings associated with BIS changes were not significantly different with or without vasoactive agents.

Tobias and Grindstaff (2005) conducted a small study, involving 12 children, that compared BIS values to nursing staff assessments of the requirement for additional sedative agents during NMB. These clinical decisions were based on assessment of autonomic variables and compared to BIS readings of 50 to 70 ; a range of BIS that had previously been used in adult studies to indicate appropriate sedation levels. The authors emphasised that additional sedative administration occurred in a third of the patients when the BIS was below 70 , thus leading to a conclusion that reliance on clinical assessment can lead to 
over-sedation. Additionally, it should be noted that the majority of children (64\%) received appropriate sedation when their BIS value was over 70 .

Lamas et al (2008b) undertook a comparison between the MLAEP and BIS response to auditory, tactile and painful stimuli in children with and without NMB. The results showed less variance in the BIS values of children with NMB compared to those without. There were statistically significant differences compared to baseline in the muscle relaxed children during auditory and painful, but not tactile, stimuli. The MLAEP of muscle relaxed children did not change during any of the stimuli.

\section{Assessing children during barbiturate coma}

Another potential benefit of DoAMs to PIC patients could be monitoring EEG burst suppression during barbiturate coma (Prins et al. 2007). Both AEP and BIS monitors provide an automated calculation of the proportion of time patients are in burst suppression (Lamas et al. 2009a). This Suppression Ratio (SR) is used to calculate the BIS and AAI indices and can also be displayed as an independent value. The pilot study by Prins et al (2007), examined SR obtained from visually inspected conventional EEG recordings and SR calculated by the BIS monitor and found that the average correlation was moderate $\left(\mathrm{r}^{2}\right.$ $=0.46)$. However, this small study only included four children, aged 3.5 to 15 years, in their correlation assessment. A larger study by Lamas and colleagues (2009a), re-examined data from Lamas et al. (2008b) and found that SR of both the BIS and AEP change according to age. SR ratios obtained from children, who were moderately or deeply sedated, were higher in children less one month of age compared to children older than one month. In addition, SR reduced with increasing age. These findings indicate cerebral maturation is an important consideration in the assessment of burst suppression using the BIS and AEP monitors (Lamas et al. 2009a). Further studies are indicated to assess the possible utility of DoAMs as monitors of barbiturate coma.

\section{DISCUSSION}

The aim of this review was to summarise the current understanding of DoAM use to monitor sedation in PIC. For a DoAM to be useful, in PIC clinical practice, as a depth of sedation 
monitor, it needs to fulfil two important criteria (Drummond 2000). Firstly, the monitors numerical output should be able to differentiate varying sedative states and secondly, that there should be no overlap of the outputs at a given clinical state (Drummond 2000). Essentially it is important for the monitor to have a high sensitivity and specificity. Ideally, this should be achieved independent of pathology or condition of the patient. In the studies described, there was a wide range and overlap of EEG values when compared to sedation scores leading to, mostly, only moderate correlations. Values obtained from EEG monitors were influenced by the clinical condition of the patient thus making them unreliable in the clinical setting. In some studies examining patient arousal, the correlation of EEG to sedation scores reduces, which is when the DoAM would be required to be at its most accurate, such as during tracheal suctioning (Berkenbosch et al. 2002) or physiotherapy (Froom et al. 2008).

The studies have been undertaken with small sample sizes. To increase sample sizes many studies employed repeated observations in the same child. This may overestimate the degree of correlation as intra-patient variability may not be the same as the inter-patient variability.

Assumptions have been made that BIS is a reliable and objective method for sedation assessment (Trope et al. 2005). A sedation monitor should ideally be evaluated against a gold standard of sedation assessment. However, there is no gold standard of sedation assessment (Twite et al. 2005). In the reviewed studies, there were several different sedation measures. Only one of these, the COMFORT sedation score, was developed and validated specifically for PIC patients. This variety of sedation measures makes it difficult to compare studies or combine data.

\section{Future research}

In the studies that compared the COMFORT scoring system with EEG monitors, the first COMFORT version was used. To obtain the composite COMFORT score involves obtaining the physiological parameters of HR and MAP. These vital signs can be altered due to factors other than sedation, such as vasoactive medications, cooling or artificial 
pace-making. In the revised COMFORT B sedation scoring system (Ista et al. 2005) the exclusion of these physiological parameters increased the reliability of the total COMFORT score (van Dijk et al. 2000). It would be of interest to examine the COMFORT B and its correlation with the DoAMs as the physiological parameters are excluded.

Utilising a monitor based on adult EEG data may be inherently flawed. DoAMs included in this review are not calibrated to accommodate EEG changes that are known to occur with age (Matoušek and Petersén 1973; McKeever et al. 2010). Lamas et al. (2009a) examined other component parameters available from the BIS and AEP monitors. This study used data from Lamas et al (2008b) and found that Spectral Edge Frequency 95\% and the suppression ratios of the BIS and AEP monitors vary with age. In an early pilot study during anaesthesia, age has been shown to influence the EEG of children (Davidson et al. 2008). This may indicate the need for a recalibration of depth of anaesthesia monitors for the paediatric population. Further research is warranted to examine the possible changes required to develop a reliable DoAM for sedation assessment in the paediatric population.

A concern not addressed in the reviewed literature relates to the impact of DoAMs to improve the outcomes of children in the intensive care. In the design of future studies this will need to be an important consideration.

\section{CONCLUSION}

DoAMs offer a potentially useful adjunct to monitoring of sedation for critically ill children. However, from the literature reviewed, utilising DoAMs in the PIC environment has not demonstrated the required accuracy to ensure that clinicians are able to reliably make conclusions about depth of sedation of individual children. A majority of the reviewed studies constitute low level evidence. A higher level of evidence is required before the DoAMs, based on adult anaesthetic research, can be promoted for use in the PIC setting. Alternative methods of cerebral monitoring, more applicable to the paediatric critical care population, might need to be developed. 


\section{References}

Alexander EW, Duane BB. Bispectral index monitoring in the intensive care unit. Pharmacotherapy 2005; 25(11):1681-2.

Ambuel B, Hamlett KW, Marx CM, Blumer JL. Assessing distress in pediatric intensive care environments: The COMFORT scale. Journal of Pediatic Psychology 1992; 17(1):95-109.

Aneja R, Heard AMB, Fletcher JE, Heard CMB. Sedation monitoring of children by the Bispectral Index in the pediatric intensive care unit. Pediatric Critical Care Medicine 2003; 4(1):60-4.

Berkenbosch JW, Fichter CR, Tobias JD. The correlation of the Bispectral Index monitor with clinical sedation scores during mechanical ventilation in the pediatric intensive care unit. Anesthesia \& Analgesia 2002; 94(3):506 - 11.

Courtman SP, Wardurgh A, Petros AJ. Comparison of the Bispectral Index monitor with the Comfort score in assessing level of sedation of critically ill children. Intensive Care Medicine 2003; 29(12):2239-46.

Crain N, Slonim A, Pollack M. Assessing sedation in the pediatric intensive care unit by using BIS and the COMFORT scale. Pediatric Critical Care Medicine 2002; 3(1):11. 4

Davidson AJ, Sale SM, Wong C, McKeever S, Sheppard S, Chan Z et al. The electroencephalograph during anesthesia and emergence in infants and children. Paediatric Anaesthesia 2008; 18(1):60-70.

De Deyne C, Struys M, Decruyenaere J, Creupelandt J, Hoste E, Colardyn F. Use of continuous bispectral EEG monitoring to assess depth of sedation in ICU patients [10.1007/s001340050765]. Intensive Care Medicine 1998; 24(12):1294-8.

Dominguez TE, Helfaer MA. Review of Bispectral Index monitoring in the emergency department and pediatric intensive care unit. Pediatric Emergency Care December 2006; 22(12):815-21.

Drummond JC. Monitoring depth of anesthesia: With emphasis on the application of the Bispectral Index and the Middle Latency Auditory Evoked Response to the prevention of recall. Anesthesiology 2000; 93(3):876-82.

Frenzel D, Greim C-A, Sommer C, Bauerle K, Roewer N. Is the bispectral index appropriate for monitoring the sedation level of mechanically ventilated surgical ICU patients? Intensive Care Medicine 2002; 28(2):178-83.

Froom SR, Malan CA, Mecklenburgh JS, Price M, Chawathe MS, Hall JE et al. Bispectral Index asymmetry and COMFORT score in paediatric intensive care patients British Journal of Anaesthesia 2008; 100(5):690-6.

Hernández-Gancedo C, Pestana D, Peña N, Royo C, Pérez-Chrzanowska H, Criado A. Monitoring sedation in critically ill patients: Bispectral index, Ramsay and observer scales. European Journal of Anaesthesiology 2006; 23(8):649-53.

Ista $E$, van Dijk M, Tibboel D, de Hoog M. Assessment of sedation levels in pediatric intensive care patients can be improved by using the COMFORT "behavior" scale. Pediatric Critical Care Medicine 2005; 6(1):58-63.

Johansen JW, Sebel PS. Development and clinical application of electroencephalographic bispectrum monitoring. Anesthesiology 2000; 93(5):1336-44.

Kurita T, Doi M, Katoh T, Sano H, Sato S, Mantzaridis H et al. Auditory evoked potential index predicts the depth of sedation and movement in response to skin incision during sevoflurane anesthesia. Anesthesiology 2001; 95(2):364-70.

Lamas A, Lopez-Herce J. Monitoring sedation in the critically ill child. Anaesthesia May 2010; 65(5):516-24.

Lamas A, Lopez-Herce J, Sancho L, Mencia S, Carrillo A, Santiago MJ et al. Assessing sedation in critically ill children by Bispectral Index, auditory-evoked potentials and clinical scales. Intensive Care Medicine 2008a; 34(11):2092-9.

Lamas A, Lopez-Herce J, Sancho L, Mencia S, Carrillo A, Santiago MJ et al. Responsiveness to stimuli of Bispectral Index, middle latency auditory evoked potentials and clinical scales in critically ill children. Anaesthesia 2008b; 63(12):1296-301. 
Lamas A, Lopez-Herce J, Sancho L, Mencia S, Carrillo A, Santiago MJ et al. Analysis of Bispectral Index and Middle Latency Auditory-Evoked Potentials parameters in critically ill children. Journal of Clinical Neurophysiology 2009a; 26(3):150-4.

Lamas A, Lopez-Herce J, Sancho L, Mencia S, Carrillo A, Santiago MJ et al. Assessment of the level of sedation in children after cardiac surgery. Annals of Thoracic Surgery 2009b; 88(1):144-50.

Long D, Horn D, Keogh S. A survey of sedation assessment and management in Australian and New Zealand paediatric intensive care patients requiring prolonged mechanical ventilation. Australian Critical Care 2005; 18(4):152-7.

Mantzaridis H, Kenny GN. Auditory evoked potential index: A quantitative measure of changes in auditory evoked potentials during general anaesthesia. Anaesthesia 1997; 52(11):1030-6.

Matoušek M, Petersén I. Frequency analysis of the EEG in normal children and in normal adolescents. In: Kellaway P, Petersén I, editors. Automation of Clinical Electroencephalography. New York: Raven Press; 1973. p.75-102

McKeever S, Johnston L, Davidson A. Changes in amplitude-integrated electroencephalogram and spectral edge frequency during paediatric general anaesthesia Anaesthesia and Intensive Care 2010; 38 (6):1124-.

Nasraway SA, Jr., Wu EC, Kelleher RM, Yasuda CM, Donnelly AM. How reliable is the Bispectral Index in critically ill patients? A prospective, comparative, single-blinded observer study. Critical Care Medicine 2002; 30(7):1483-7.

National Health and Medical Research Council. (1999a). A guide to the development, implementation and evaluation of clinical practice guidelines. Canberra: Commonwealth of Australia.

National Health and Medical Research Council. (1999b). How to review the evidence: Systematic identification and review of the scientific literature. Canberra: Commonwealth of Australia.

Nishiyama T, Hanaoka K. The A-line ARX index may be a more sensitive detector of arousal than the bispectral index during propofol-fentanyl-nitrous oxide anesthesia: A preliminary investigation. Canadian Journal of Anesthesia / Journal canadien d'anesthésie 2004; 51(6):539-44.

Parkinson L, Hughes J, Gill A, Billingham I, Ratcliffe J, Choonara I. A randomized controlled trial of sedation in the critically ill. Pediatric Anesthesia 1997; 7(5):405-510.

Playfor $\mathrm{S}$. The use of bispectral index monitors in paediatric intensive care. Critical Care 2005; 9(1):25 - 6.

Playfor SD, Thomas DA, Choonara I. Sedation and neuromuscular blockade in paediatric intensive care: A review of current practice in the UK. Pediatric Anesthesia 2003; 13(2):147-51.

Prins S, de Hoog M, Blok J, Tibboel D, Visser G. Continuous noninvasive monitoring of barbiturate coma in critically ill children using the Bispectral ${ }^{\mathrm{TM}}$ index monitor. Critical Care 2007; 11(5):R108.

Rampil IJ. A primer for EEG signal processing in anesthesia. Anesthesiology 1998; 89(4):980-1002.

Ramsay MA, Savege TM, Simpson BR, Goodwin R. Controlled sedation with alphaxalonealphadolone. British Medical Journal 1974; 2(5920):656-9.

Riker RR, Picard JT, Fraser GL. Prospective evaluation of the Sedation - Agitation Scale for adult critically ill patients. Critical Care Medicine 1999; 27(7):1325-9.

Rinaldi S, Consales G, De Gaudio AR. Sedation monitoring in ICU. Current Anaesthesia \& Critical Care 2006; 17(5):303-15.

Rosow C, Manberg PJ. Bispectral index monitoring. Anesthesiology Clinics of North America 2001; 19(4):947-66.

Sadhasivam S, Ganesh A, Robison A, Kaye R, Watcha MF. Validation of the Bispectral Index monitor for measuring the depth of sedation in children. Anesthesia and Analgesia 2006; 102(2):383 - 8.

Sakai T, Singh H, Mi WD, Kudo T, Matsuki A. The effect of ketamine on clinical endpoints of hypnosis and EEG variables during propofol infusion. Acta Anaesthesiologica Scandinavica 1999; 43(2):212-6.

Schmidt T. Learning under anesthesia: Checking the light in the fridge? . Consciousness \& Cognition 2006; 15(1):24-7. 
Simmons LE, Riker RR, Prato BS, Fraser GL. Assessing sedation during intensive care unit mechanical ventilation with the Bispectral Index and the Sedation-Agitation Scale. Critical Care Medicine 1999; 27(8):1499-504.

Suzuki M, Edmonds HL, Tsueda K, Malkani AL, Roberts CS. Effect of ketamine on Bispectral Index and levels of sedation. Journal of Clinical Monitoring and Computing 1998; 14(5):373.

Tempe DK. In search of a reliable awareness monitor. Anesthesia \& Analgesia 2001; 92(4):801-4.

Thornton C, Sharpe RM. Evoked responses in anaesthesia. British Journal of Anaesthesia 1998; 81(5):771-81.

Tobias J. Tolerance, withdrawal, and physical dependency after long-term sedation and analgesia of children in the pediatric intensive care unit. Critical Care Medicine 2000; 28(6):2122-32.

Tobias JD. Monitoring the depth of sedation in the pediatric ICU patient: Where are we, or more importantly, where are our patients? Pediatric Critical Care Medicine 2005; 6(6):715-8.

Tobias JD, Grindstaff R. Bispectral Index monitoring during the administration of neuromuscular blocking agents in the pediatric intensive care unit patient. Journal of Intensive Care Medicine 2005; 20(4):233 - 8.

Triltsch AE, Nestmann G, Orawa H, Moshirzadeh M, Sander M, Grosse J et al. Bispectral Index versus COMFORT score to determine the level of sedation in paediatric intensive care unit patients: A prospective study. Critical Care 2005; 9(1):R9-R17.

Trope RM, Silver PC, Sagy M. Concomitant assessment of depth of sedation by changes in Bispectral Index and changes in autonomic variables (heart rate and/or BP) in pediatric critically ill patients receiving neuromuscular blockade. Chest 2005; 128(1):303-7.

Twite MD, Zuk J, Gralla J, Friesen RH. Correlation of the Bispectral Index monitor with the COMFORT scale in the pediatric intensive care unit. Pediatric Critical Care Medicine 2005; 6(6):648-53.

Valsangiacomo E, Schmid ER, Schüpbach RW, Schmidlin D, Molinari L, Waldvogel K et al. Early postoperative arrhythmias after cardiac operation in children. The Annals Of Thoracic Surgery 2002; 74(3):792-6.

van Dijk M, de Boer JB, Koot HM, Tibboel D, Passchier J, Duivenvoorden HJ. The reliability and validity of the COMFORT scale as a postoperative pain instrument in 0 to 3 year-old infants. Pain 2000; 84(2-3):367-77.

Zuppa AF, Adamson PC, Mondick JT, Davis LA, Maka DA, Narayan M et al. Drug utilization in the pediatric intensive care unit: Monitoring prescribing trends and establishing prioritization of pharmacotherapeutic evaluation of critically ill children. Journal of Clinical Pharmacology 2005; 45(11):1305-12. 